Supplementary Information

\title{
Prussian Blue-Viologen Inorganic-Organic Hybrid Blend for Improved Electrochromic Performance
}

Anjali Chaudhary, Devesh K. Pathak, Manushree Tanwar, Pankaj R. Sagdeo and Rajesh Kumar* Material Research Laboratory, Discipline of Physics \& MEMS, Indian Institute of Technology

Indore, Simrol-453552, India

*Corresponding author e-mail: rajeshkumar@iiti.ac.in

$* * * * * * * * * * * * * * * * * *$

Steps involved in the synthesis of Prussian blue film:

1. A solution of $0.01 \mathrm{M} \mathrm{K}_{3}\left[\mathrm{Fe}(\mathrm{CN})_{6}\right], 0.01 \mathrm{M} \mathrm{FeCl}_{3}$ and $0.05 \mathrm{M} \mathrm{KCl}$ was taken in three electrode system, where $\mathrm{Ag} / \mathrm{AgCl}$ as reference electrode, Platinum wire as counter electrode and ITO coated glass as working electrode were used.

2. Deposition of Prussian blue (PB) film on ITO substrate was carried out under a current density of $-50 \mu \mathrm{A} / \mathrm{cm}^{2}$ for 300 seconds. Then, as deposited Prussian blue films were annealed at $50^{\circ} \mathrm{C}$ for 60 minutes.

3. Before device fabrication process, $\mathrm{PB}$ films dipped in $0.1 \mathrm{M} \mathrm{LiClO}_{4}$ propylene carbonate electrolyte at $-0.4 \mathrm{~V}$ for 30 seconds as per the recipe suggested by Bi et al. ${ }^{2}$

$* * * * * * * * * * * * * * * * * * * * * * * * * * * * * * * * * * * * * * * * *$ 


\section{Device fabrication recipe:}

1. A solution of $4 \mathrm{wt} \%$ ethyl viologen diperchlorate (EV) and $5 \mathrm{wt} \% \mathrm{PEO}$ in acetonitrile were prepared and mixed in a ratio of 1:1.

2. The PEO solution was first filtered through a $0.45 \mu \mathrm{m}$ PTFE filter paper before adding it to EV solution, then $20 \mu \mathrm{l}$ of above solution was drop casted on ITO coated glass substrate.

3. The above drop casted EV electrode is sandwiched with PB coated electrode to fabricate a device.

$* * * * * * * * * * * * * * * * * * * * * * * * * * * * * * * * * * * * * * * * * * *$

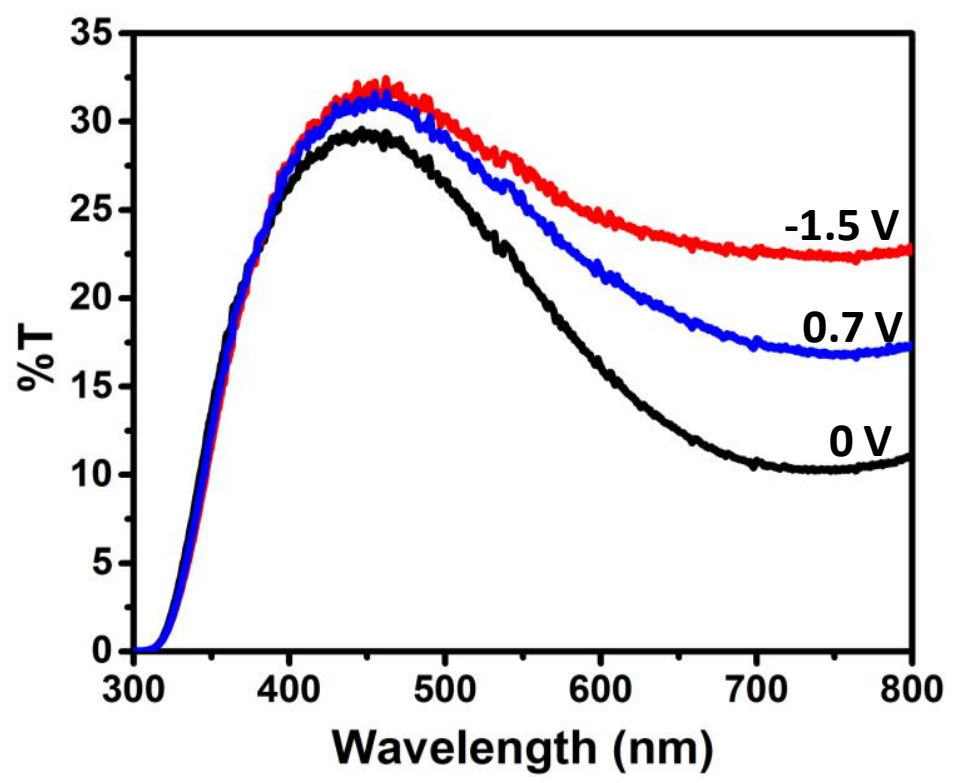

Figure S1: In situ transmission spectra of device containing only Prussian blue as its active material at different bias having optical modulation of $28 \%$ between $0.7 \mathrm{~V}$ and -1.5 V bias. 


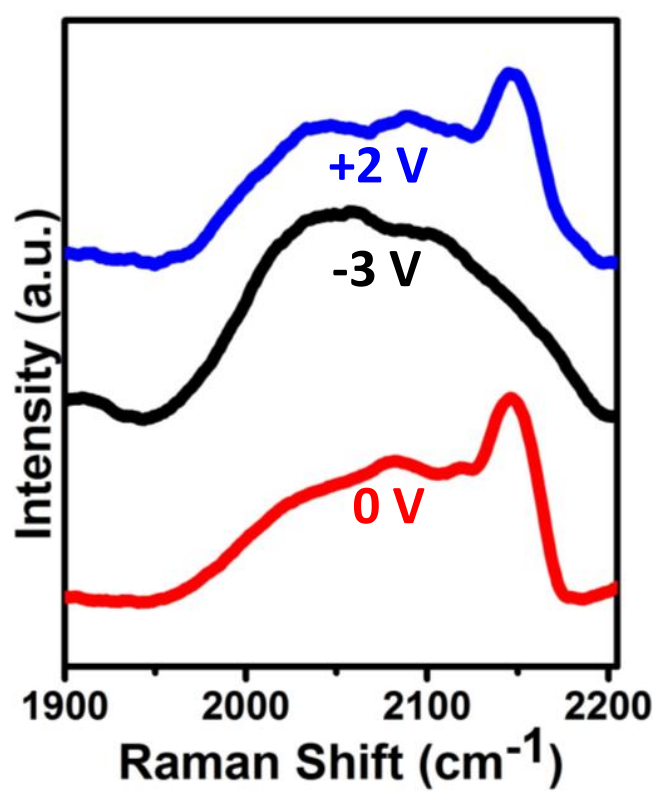

Figure S2: Controlled Raman spectra of device containing only Prussian blue.

Table S1: Comparison of various devices consisting prussian blue as one of its active material.

\begin{tabular}{|c|c|c|c|c|}
\hline S.No. & $\begin{array}{c}\text { Coloration } \\
\text { Efficiency }\end{array}$ & Material components & $\begin{array}{c}\text { Switching } \\
\text { time (s) }\end{array}$ & References \\
\hline 1. & 135 & $\mathrm{~PB}+\mathrm{TiO}_{2}$ & 3,2 & 1 \\
\hline 2. & 139.4 & $\mathrm{~PB}+\mathrm{WO}_{3}$ & $1.84,1.95$ & 2 \\
\hline 3. & 86.7 & $\mathrm{~PB}+$ Pani & Not reported & 3 \\
\hline 4. & 157 & $\mathrm{~PB}+$ polybutylviologen & 10 & 4 \\
\hline 5. & 150 & $\mathrm{~PB}$ & 3.4 & 5 \\
\hline
\end{tabular}

\section{I-V Characteristic of solid state electrochromic device:}

I-V characteristic (a two terminal Cyclic Voltammogram) of the reported device is given in Figure S3 with scanning direction shown. Initially, while scanning from $0 \mathrm{~V}$ to $-1.5 \mathrm{~V}$ there is little net current flow in the device until a bias of $1.5 \mathrm{~V}$ is applied to convert the whole film into 
PW. In the reverse scan, current flows in the device due to PW $\rightarrow$ PB conversion as a result of oxidation at anode supported by simultaneous reduction of $\mathrm{EV}^{+2}$ to $\mathrm{EV}^{+\bullet}$ taking place at the cathode and hence completing the charge flow in the device (increase in current is observed in Figure S3, the positive quadrant). This results in changing a transparent device (OFF, $-1.5 \mathrm{~V})$ to a blue colored device $(\mathrm{ON}, 0.7 \mathrm{~V})$. Various redox and supporting ion movement can be understood via following mechanism:

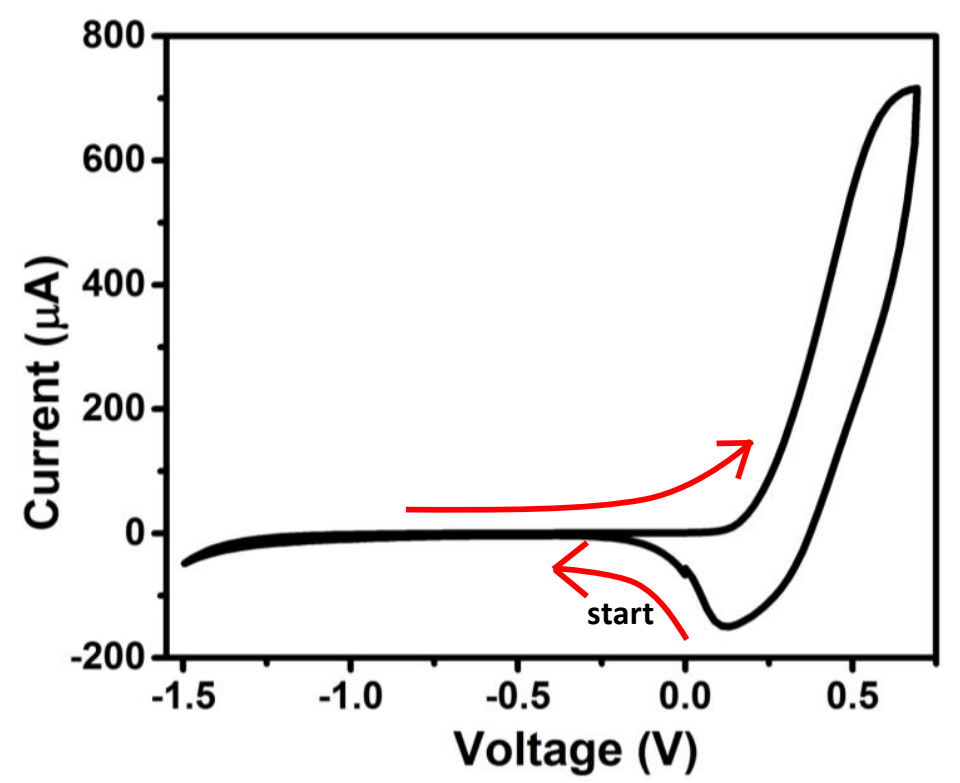

Figure S3: Cyclic I-V of fabricated solid state device containing PB and EV. The voltage on Xaxis is with respect to PB electrode.

\section{Step1: During pre-device fabrication process.}

When as prepared PB film was dipped in $0.1 \mathrm{M} \mathrm{LiClO}_{4}$ solution under $-0.4 \mathrm{~V}$ bias for $30 \mathrm{~s}$, it converts PB film into PW film partially having an overall sky blue color. It is important here to mention that this pre-fabrication step allows some of the PB molecules to convert to PW and allowing $\mathrm{Li}+$ ions to penetrate in the film to support the $\mathrm{PB} \rightarrow \mathrm{PW}$ conversion. Due to the 
positive bias to the electrode, $\mathrm{Li}+$ ion wandering in the electrolyte $\left(\mathrm{LiClO}_{4}\right)$ gets adsorbed (to be used in the switching step later) on the film due to Coulombic pull. To make the whole process clear let us suppose that the pristine PB film contains " $n$ " number of PB molecules are attached to the substrate and during the pre-fabrication process, some number (say $n-\delta$ ) of molecules get converted to PW due to the application of negative bias and presence of $\mathrm{Li}^{+}$ions in the solution which can be understood from the equation below. Surface of the film also intercalated with some amount of $\mathrm{Li}^{+}$ions on the film resulting in the process below:

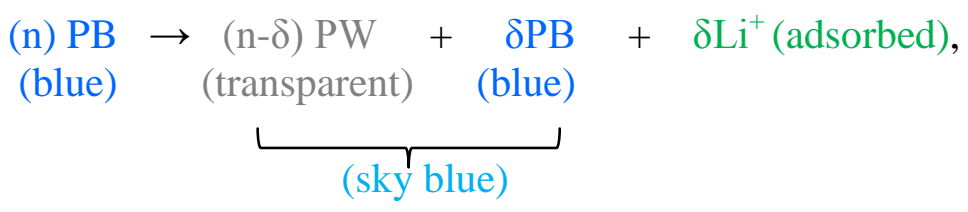

\section{Step 2: During device operation}

A. 0 to $-1.5 \mathrm{~V}$ Scan: Initially the device is sky blue in appearance due to the presence of sky blue electrode obtained above after the pre-fabrication step (Eq. S1). At -1.5 V bias (Figure S4) the device appearance changes to transparent from sky blue as a result of following process:

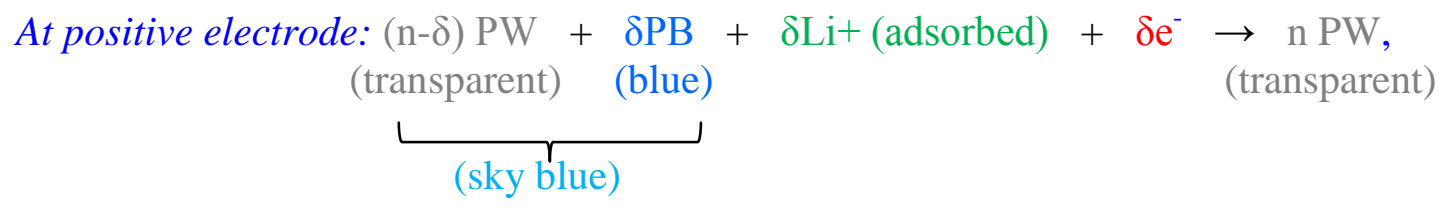

At negative electrode: No reaction, leading to no current flow through the device. This process leads to the transparent (OFF) state of the device.

B. $-1.5 \mathrm{~V}$ to $0.7 \mathrm{~V}$ Scan: Following process is the likely taking place during this scan:

At positive electrode: $\underset{\text { (transparent) }}{\mathrm{n} \mathrm{PW}} \underset{\text { (blue) }}{\mathrm{n} \mathrm{PB}}+\mathbf{n e}^{-}+\mathrm{n} \mathrm{Li}^{+}$, 
At negative electrode: $\underset{\text { (transparent) }}{\mathrm{EV}^{+2}+\mathrm{ne}^{-}} \rightarrow \underset{\text { (blue) }}{\mathrm{EV}^{+\bullet}}$,

Above two processes will yield a blue colored device (ON state).

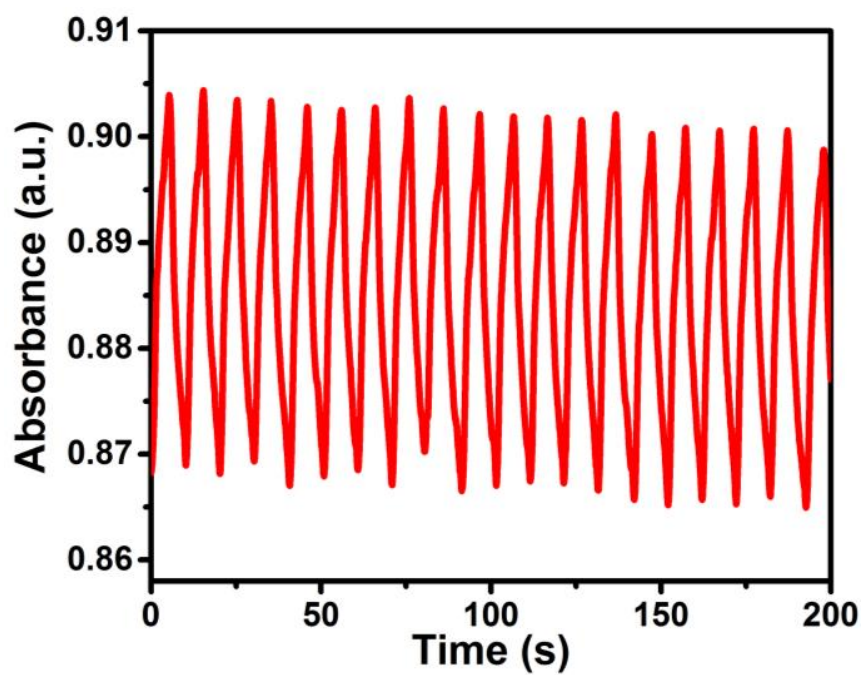

Figure S4: Absorbtion kinetics of device containing only PB as its active material. 
References:

(1) Seelandt, B.; Wark, M. Electrodeposited Prussian Blue in Mesoporous TiO2 as

Electrochromic Hybrid Material. Microporous and Mesoporous Materials 2012, 164, 67-70.

(2) Bi, Z.; Li, X.; Chen, Y.; He, X.; Xu, X.; Gao, X. Large-Scale Multifunctional

Electrochromic-Energy Storage Device Based on Tungsten Trioxide Monohydrate Nanosheets and Prussian White. ACS Appl. Mater. Interfaces 2017, 9 (35), 29872-29880.

(3) Duek, E. A. R.; Paoli, M.-A. D.; Mastragostino, M. A Solid-state Electrochromic Device Based on Polyaniline, Prussian Blue and an Elastomeric Electrolyte. Advanced Materials 1993, 5 (9), 650-652.

(4) Fan, M.-S.; Kao, S.-Y.; Chang, T.-H.; Vittal, R.; Ho, K.-C. A High Contrast Solid-State Electrochromic Device Based on Nano-Structural Prussian Blue and Poly(Butyl Viologen) Thin Films. Solar Energy Materials and Solar Cells 2016, 145, 35-41.

(5) J. Mortimer, Roger; R. Reynolds, John; In situ colorimetric and composite coloration efficiency measurements for electrochromic Prussian blue, Journal of Materials Chemistry, 2005, 15, 22, 2226-2233. 